\title{
Serotonin Stimulates Phosphorylation of Aplysia Synapsin and Alters Its Subcellular Distribution in Sensory Neurons
}

\author{
Annie Angers, ${ }^{*}$ Diasinou Fioravante, ${ }^{*}$ Jeannie Chin, Leonard J. Cleary, Andrew J. Bean, and John H. Byrne \\ Department of Neurobiology and Anatomy, W. M. Keck Center for the Neurobiology of Learning and Memory, \\ The University of Texas-Houston Medical School, Houston, Texas 77030
}

\begin{abstract}
Only a small fraction of neurotransmitter-containing synaptic vesicles (SVs), the readily releasable pool, is available for fast $\mathrm{Ca}^{2+}$-induced release at any synapse. Most SVs are sequestered at sites away from the plasma membrane and cannot be exocytosed directly. Recruitment of SVs to the releasable pool is thought to be an important component of short-term synaptic facilitation by serotonin (5-HT) at Aplysia sensorimotor synapses. Synapsins are associated with SVs and hypothesized to play a central role in the regulation of SV mobilization in nerve terminals. Aplysia synapsin was cloned to examine its role in synaptic plasticity at the well characterized sensorimotor neuron synapse of this animal. Acute 5-HT treatment of ganglia induced synapsin phosphorylation. Immunohistochemical anal-
\end{abstract}

Recruitment of synaptic vesicles (SVs) to the releasable pool may play an important role in short-term heterosynaptic facilitation of the sensorimotor synapse in Aplysia (Byrne and Kandel, 1996) and in determining the extent of depression of neurotransmitter release during low-frequency activity (Byrne, 1982; Gingrich and Byrne, 1985). Although a mobilization process has been hypothesized in these two examples of synaptic plasticity, little is known about the molecular mechanisms underlying vesicle trafficking at Aplysia sensorimotor synapses.

Synapsin is a SV-associated protein suggested to be a central element in the organization and regulation of the pool of vesicles in nerve terminals (Greengard et al., 1993; Rosahl et al., 1993, 1995; Li et al., 1995; Chi et al., 2001). Many of the molecular features of synapsin suggest that it plays a regulatory role in the mobilization process presumed to be involved in short-term synaptic depression and facilitation. Synapsin associates with SVs (Huttner et al., 1983; Valtorta et al., 1988; Benfenati et al., 1989, 1992) and interacts with actin, spectrin, and microtubules (De Camilli et al., 1990; Greengard et al., 1993; Matsubara et al., 1996; Zimmer et al., 2000). The binding capacities of synapsin I are impaired after phosphorylation (Schiebler et al., 1986; Bähler and Greengard, 1987; Matsubara et al., 1996; Hosaka et al., 1999;

\footnotetext{
Received Feb. 1, 2002; revised April 4, 2002; accepted April 12, 2002.

This work was supported by the W. M. Keck Foundation, the Mallinckrodt Foundation (A.J.B.), National Institutes of Health (NIH) fellowship MH12107 (J.C.), and NIH Grants NS38100 (L.J.C.), MH58920 (A.J.B.), and NS19895 (J.H.B.). We thank Dr. K. C. Martin (University of California Los Angeles) for the VAMP antibody and Dr. L. DesGroseillers (Université de Montréal) for the Aplysia cDNA library. We also thank G. A. Phares and E. Antzoulatos for helpful discussions and J. Liu and J. Foxx for technical assistance.

*A.A. and D.F. contributed equally to this work.

Correspondence should be addressed to Dr. John H. Byrne, Department of Neurobiology and Anatomy, The University of Texas-Houston Medical School, P.O. Box 20708, Houston, TX 77225. E-mail: john.h.byrne@uth.tmc.edu. Copyright (C) 2002 Society for Neuroscience $0270-6474 / 02 / 225412-11 \$ 15.00 / 0$
}

yses of cultured Aplysia neurons revealed that synapsin is distributed in distinct puncta in the neurites. These puncta are rapidly dispersed after treatment of the neurons with 5-HT. The dispersion of synapsin puncta by $5-\mathrm{HT}$ was fully reversible after washout of the modulator. Both 5-HT-induced phosphorylation and dispersion of synapsin were mediated, at least in part, by CAMP-dependent protein kinase and mitogen-activated protein kinase. These experiments indicate that synapsin and its regulation by 5 -HT may play an important role in the modulation of SV trafficking in short-term synaptic plasticity.

Key words: synapsin; Aplysia; 5-HT; serotonin; synaptic vesicles; short-term plasticity; mobilization; PKA; MAPK; phosphorylation
Jovanovic et al., 2000), suggesting that synapsin is responsible for the regulation of SV mobilization (Turner et al., 1999; Chi et al., 2001).

All synapsin isoforms share a consensus sequence for protein kinase A (PKA) and calcium-calmodulin-dependent kinase I/IV (CAMK I/IV) phosphorylation in the small N-terminal A domain (Südhof et al., 1989; Kao et al., 1999; Chi et al., 2001). Phosphorylation of this domain controls association with SVs (Hosaka et al., 1999). Phosphorylation of synapsin I by CAMK II and mitogen-activated protein kinase (MAPK) regulates its interactions with the cytoskeleton (Bähler and Greengard 1987; Jovanovic et al., 1996; Matsubara et al., 1996) and also SVs (Chi et al., 2001). MAPK phosphorylation has been suggested to mediate the enhancement of neurotransmitter release induced by BDNF in rodent synaptosomes (Jovanovic et al., 2000).

Protein phosphorylation plays an important role in the mechanisms underlying 5-HT-induced facilitation of Aplysia sensory neurons (SNs) (Byrne and Kandel, 1996). Two-dimensional gel analysis revealed that the phosphorylation state of at least 20 proteins is modified by treatment with 5-HT (Sweatt and Kandel, 1989; Homayouni et al., 1995). However, only a few of these proteins have been identified (Homayouni et al., 1997). In the present study, we have cloned the cDNA encoding Aplysia synapsin (apSyn) and examined its regulation by 5-HT.

We found that apSyn is acutely phosphorylated in ganglia exposed to 5-HT in a protocol that induces short-term facilitation in SNs. Moreover, similar treatment of cultured SNs alters the subcellular distribution of apSyn, which may reflect the dissociation of the protein from SVs. apSyn dispersion occurs within seconds of 5-HT application and recovers by $2 \mathrm{hr}$ after removal of 5-HT. Both 5-HT-induced apSyn phosphorylation and dispersion are blocked by inhibitors of PKA and MAPK. These results provide the first evidence suggesting that the mechanisms under- 
lying 5-HT-induced short-term facilitation may involve synapsin, indicating that MAPK could play a previously unsuspected role in short-term facilitation and depression.

Preliminary reports of these results have been published previously in abstract form (Angers et al., 1999, 2000; Fioravante et al., 2001).

\section{MATERIALS AND METHODS}

Cloning. Aplysia CNS cDNAs were amplified by PCR using nested degenerated primers corresponding to highly conserved amino acid sequences in the central $\mathrm{C}$ domain of vertebrate and Drosophila synapsins: outer sense primer: $5^{\prime}-\mathrm{TT}(\mathrm{C} / \mathrm{T}) \mathrm{AA}(\mathrm{A} / \mathrm{G}) \mathrm{CCIGA}(\mathrm{C} / \mathrm{T}) \mathrm{TT}(\mathrm{C} / \mathrm{T}) \mathrm{GTI}(\mathrm{C} / \mathrm{T}) \mathrm{TIATI}(\mathrm{A} /$ C)GICA-3'; outer antisense primer: 5'-IGCIGAICC-(C/T)TG(A/ G)TTIGT(C/T)TTCCA(A/G)TTICC-3'; inner sense primer: 5'-GA(C/ T)AA(A/G)CCITGGGTITT(C/T)GCICA-3'; inner antisense primer: 5'CAT(A/G)(A/T)AIGC(C/T)TT(A/G)TA(A/G)TT(A/G)TTICC-3'. This procedure generated a $278 \mathrm{bp}$ product further used as a probe in a high-stringency screen of an Aplysia CNS cDNA library constructed in $\lambda$ ZapII (kind gift of Dr. L. DesGroseillers, Université de Montréal). Several clones were isolated, representing a total of four different isoforms. The longest cDNAs for all isoforms were entirely sequenced on both strands (see supplementary Fig. S1). apSyn sequences were deposited in the GenBank database under accession numbers AF287982, AF287983, AF287984, and AF287985.

Antibody. A polyclonal antibody against apSyn was produced in rabbits by injection of recombinant apSyn (rec-apSyn) (AF287982) (Cocalico Bologicals Inc.). To obtain recombinant apSyn, the coding region of the cDNA was subcloned in the pGEX-4T vector, in fusion with the glutathione $S$-transferase (GST) protein. The recombinant protein (recapSyn) was produced in Escherichia coli, purified on glutathione beads, and cleaved with thrombin to remove the GST portion. Antisera specificity was verified by Western blot and immunoprecipitation of tissue extracts and purified recombinant apSyn (see Fig. 2).

Phosphorylation. Pleural-pedal ganglia were obtained from mature animals weighing 100-200 gm with either (Alacrity Marine Biologicals, Redondo Beach, CA; Marinus, Long Beach, CA). Paired ganglia were removed and divided into control and experimental groups. The ganglia were labeled by overnight incubation in artificial seawater (ASW) $(10 \mathrm{~mm}$ $\mathrm{CaCl}_{2}, 10 \mathrm{~mm} \mathrm{KCl}, 50 \mathrm{~mm} \mathrm{MgCl}{ }_{2}, 440 \mathrm{~mm} \mathrm{NaCl}, 100 \mu \mathrm{g} / \mathrm{ml}$ streptomycin, $100 \mu \mathrm{g} / \mathrm{ml}$ penicillin-G, $30 \mathrm{~mm}$ HEPES, $\mathrm{pH}$ 7.5) containing 100 $\mu \mathrm{Ci} / \mathrm{ml}{ }^{32} \mathrm{P}$ (Homayouni et al., 1995). 5-HT (50 $\mu \mathrm{M}$ final concentration) was added for a period of $5 \mathrm{~min}$ at the end of the labeling period. The control ganglia were always the second ganglia removed from the same animal, and they systematically received equivalent amounts of vehicle (i.e., $\mathrm{H}_{2} \mathrm{O}$ ). Kinase inhibitors (KT5720, $10 \mu \mathrm{M}$; staurosporine, $50 \mu \mathrm{M}$; or U0126, $20 \mu \mathrm{M}$ ) were applied $1 \mathrm{hr}$ before 5-HT treatment, at the end of the labeling period. Immediately after the end of treatment, each ganglion was homogenized in $50 \mu \mathrm{l}$ ice-cold homogenization buffer (1\% SDS, 10 mM EDTA, $20 \mathrm{~mm}$ Tris, $\mathrm{pH}$ 7.5, $1 \mathrm{~mm}$ Na orthovanadate, $1 \mathrm{~mm}$ DTT, 2 m NaF, 2 mm NaPPi, $0.5 \mathrm{~mm}$ okadaic acid, $1 \mathrm{~mm}$ PMSF, $1 \%$ Sigma protease inhibitors mixture). The protein concentration of each sample was determined by a Bradford assay (Bio-Rad), and equal amounts of protein were diluted into $5 \mathrm{vol}$ of immunoprecipitation (IP) buffer (20 mm HEPES pH 7.4, $100 \mathrm{~mm} \mathrm{NaCl}, 1 \%$ Triton X-100, and protease inhibitors). The protein samples were precleared with protein A-Sepharose and incubated with 1:200 vol of apSyn antibody coupled to protein A-Sepharose for $16 \mathrm{hr}$ at $4^{\circ} \mathrm{C}$. The beads were washed extensively in IP buffer, and bound protein was released after addition of SDSPAGE sample buffer. Proteins were resolved on 10\% SDS-PAGE and transferred to nitrocellulose membrane. The level of apSyn phosphorylation stimulated by 5 -HT was quantified by measuring the intensity of the ${ }^{32} \mathrm{P}$ signal with a phosphorimager and calculating the ratio of the signals from treated and control samples for each experiment. After the procedure, the membranes were immunoblotted with the anti-apSyn antibody to verify that equivalent amounts of total synapsin had been immunoprecipitated from both control and treated ganglia. For each sample, the intensity of the signal obtained on the immunoblot differed by $<10 \%$ for treated and control, as measured with the quantification program Imagequant.

Cell culture and treatments. Culturing procedures followed those described previously (Schacher and Proshansky, 1983; Rayport and Schacher, 1986; Martin et al., 1997a,b; Chin et al., 1999). Motor neurons (MNs) were isolated from abdominal ganglia from juvenile animals $(0.8-1.5 \mathrm{gm})$, and SNs were isolated from pleural ganglia from $60-100$ gm animals (NIH-Aplysia resource facility, University of Miami, Miami, FL). Cells were maintained in culture $5 \mathrm{~d}$ before experiments.

Cultures were treated with $5-\mathrm{HT}(50 \mu \mathrm{l}$ of a $50 \mu \mathrm{M}$ bolus, $1 \mu \mathrm{M}$ final bath concentration; see below) or vehicle for $5 \mathrm{~min}$ before fixation. For the experiments with kinase inhibitors, KT5720 (10 $\mu \mathrm{M}$ final bath concentration), U0126 (20 $\mu \mathrm{M}$ final bath concentration), or vehicle (DMSO, $0.075 \%$ final bath concentration) was added to the cultures $1 \mathrm{hr}$ before 5-HT treatment. For the experiments that examined the dispersion of synapsin, cultures were treated with 5 - $\mathrm{HT}$ or vehicle $\left(\mathrm{H}_{2} \mathrm{O}\right)$ for $5 \mathrm{~min}$, which was subsequently washed out with 5 complete vol of media. Cultures were then fixed at the indicated time points with PBS containing $30 \%$ sucrose and $4 \%$ paraformaldehyde.

For the electrophysiological experiment, EPSPs were recorded in a MN cocultured with a single SN using techniques similar to those described by Martin et al. (1997a,b). A baseline EPSP was first recorded in each coculture to verify the presence of a synaptic connection. After a minimum recovery period of $1 \mathrm{hr}$, a train of 25 EPSPs was elicited at 1 $\mathrm{Hz}$ in the control group. Amplitudes of EPSPs were normalized to the baseline value (see above) recorded before the first EPSP in the train. In the experimental group, synaptic facilitation was induced after the 10th EPSP by delivering a $50 \mu \mathrm{l}$ bolus of $50 \mu \mathrm{M} 5$-HT to the chamber in close proximity to the culture ( $1 \mu \mathrm{M}$ final bath concentration; see below).

To provide an estimate of the concentration of 5-HT to which cultured cells were exposed during bath applications, a separate experiment was conducted in which the change in optical density (OD) of a dye (hematoxylene) was measured. The dye was applied in a similar way to 5-HT, and samples of the media were collected from the center of the culture dish immediately, $30 \mathrm{sec}$, and $5 \mathrm{~min}$ after. The OD of the samples was measured at $400 \mathrm{~nm}$, and the dilution of the dye was calculated, providing an estimate of the final bath concentration of 5-HT at various time points. Results indicated that immediately after bath application of 5-HT, cultured neurons were exposed to $\sim 5 \mu \mathrm{M}$ 5-HT (data not shown). The 5-HT concentration was estimated to have dropped to $4 \mu \mathrm{M}$ within $30 \mathrm{sec}$, and by $5 \mathrm{~min}$ it had reached its final value $(1 \mu \mathrm{M})$.

Immunohistochemistry. Immunohistochemical procedures followed those of Chin et al. (1999). Briefly, cells or ganglia sections were fixed in a solution of $4 \%$ paraformaldehyde in PBS containing 30\% sucrose. After three rinses in PBS, the fixed cells were blocked for $2 \mathrm{hr}$ at room temperature in $\mathrm{PBS} / 0.1 \%$ Triton $\mathrm{X}-100 / 2 \%$ normal goat serum and subsequently incubated overnight at $4^{\circ} \mathrm{C}$ with anti-apSyn antibody $(1: 500)$ or affinity-purified anti-VAMP antibody (1:500, kind gift of Dr. K. C. Martin, University of California Los Angeles) diluted in blocking solution. Secondary antibody (tetramethylrhodamine-conjugated goat antirabbit IgG or Alexa 598-conjugated goat anti-rabbit IgG, both at 1:100 dilution) was applied in the same blocking solution for $2 \mathrm{hr}$ at room temperature. Slides were then mounted using Prolong antifade medium (Molecular Probes). Images were obtained with a Bio-Rad 1024 MP confocal microscope using a $10 \times$ lens or a $60 \times$ oil immersion lens (numerical aperture 1.4) and consisted of projections through 10-15 $\mu \mathrm{m}$ of optical sections. Because it was not possible to image the entire cell at high magnification, a single field was selected from each cell that included the maximum number and length of neurites. Selection was made in bright field before fluorescence detection. Images were stacked and analyzed with the Metamorph Offline software (Universal Imaging Corporation). Fluorescent puncta were oblong in shape, with mean $( \pm$ SEM $)$ longitudinal axis $1.04 \pm 0.04 \mu \mathrm{m}$ and transverse axis $0.91 \pm 0.03 \mu \mathrm{m}$. Puncta were counted manually, and the length of neurites was measured using the analysis software. Measurements were performed by an individual who was unaware of the experimental manipulation of each cell.

The processes in cocultures were very complex and extended. Therefore, an $8 \times 8$ grid was superimposed over the confocal images, and measurements were obtained as described above but just in three randomly chosen regions of the grid. This sampling procedure was unnecessary for isolated SNs because of the less complex nature of the arborization. Similar to the SNs, the shape of the puncta in the cocultures was oblong, although their size tended to be larger, with mean longitudinal axis $2.32 \pm 0.08 \mu \mathrm{m}$ and transverse axis $2.07 \pm 0.07 \mu \mathrm{m}$.

\section{RESULTS}

\section{Cloning of Aplysia synapsin isoforms}

Screening of an Aplysia cDNA library yielded four homologous sequences. These sequences were identical throughout, except for two inserted sequences and one possible substitution (Fig. $1 \mathrm{~A}$; red characters in on-line supplemental Fig. S1). Southern blot analysis 
A

Figure 1. Cloning of Aplysia synapsins (apSyn). A, Schematic representation of the synapsin cDNAs. The open boxes represent the untranslated regions, and the filled boxes represent the open reading frame. Alternative exons are represented above and below their site of insertion. $B$, Comparison of the domain structure and homology of Aplysia synapsin protein with squid, Drosophila, and human synapsin Ia. The degree of sequence identity between Aplysia and other synapsins is indicated above each identified domain. Variable regions in apSyn are shown in red.

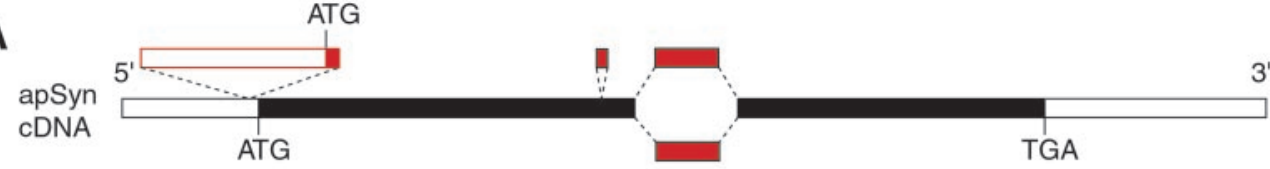

B

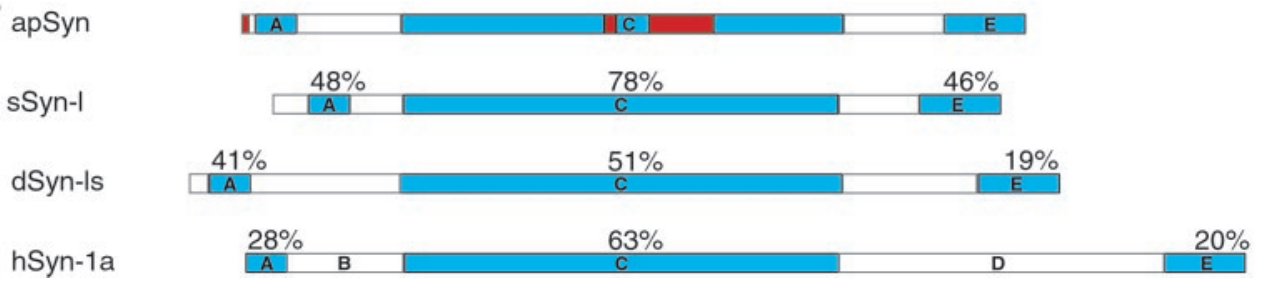

of genomic DNA suggested that apSyn is encoded by a single gene (data not shown). Thus, the various cDNAs isolated from the library are likely generated by alternative splicing of a single transcript. Consistent with our sequence data, Northern blot analysis of RNA isolated from different tissues showed two major mRNAs of 2.5 and $2.8 \mathrm{~kb}$, respectively, expressed exclusively in the CNS (data not shown). The position of the intron-exon boundaries indicated by these alternative splicing events is perfectly conserved in human synapsin I (Südhof, 1990).

apSyn has the same domain arrangement as other vertebrate and invertebrate synapsins (Fig. 1B) (Klagges et al., 1996; Hilfiker et al., 1998; Kao et al., 1999). The short N-terminal A domain is well conserved, whereas low but significant amino acid identity is present in the C-terminal $\mathrm{E}$ domain (Fig. 1B; and on-line supplemental Fig. S1). The degree of sequence identity is highest (51-78\%) for the central C domain.

Potential regulatory sites are distributed throughout the apSyn sequence (see on-line supplemental Fig. S1). In addition to the PKA/CAMK I/IV phosphorylation site in the A domain (on-line supplemental Fig. S1, circled residue), two potential MAPK phosphorylation sites (on-line supplemental Fig. S1, squared amino acids) were identified. Despite the absence of sequence conservation in this region of the protein, two MAPK phosphorylation sites were also identified in this domain of mammalian synapsin I (Jovanovic et al., 1996; Matsubara et al., 1996). Several protein kinase C (PKC) consensus sequences are dispersed throughout the apSyn sequence (on-line supplemental Fig. S1, diamonds). The region containing the CAMK II sites in mammalian synapsin I is absent from the Aplysia homolog (on-line supplemental Fig. $\mathrm{S} 1$ ), and no consensus sequence for this enzyme is present in apSyn.

\section{Antibody specificity and apSyn tissue distribution}

Rec-apSyn was generated in E. coli and used as an antigen to generate a polyclonal antibody to examine the distribution and phosphorylation of synapsin in Aplysia. The antibody recognized rec-apSyn and a protein of roughly $57 \mathrm{kDa}$ in Aplysia CNS, whereas no bands were detected in other tissue extracts (Fig. 2A). This result suggests that apSyn expression is limited to the CNS. The specificity of the antibody is demonstrated in Figure $2 B$, in which neither preimmune serum nor antiserum preabsorbed with excess rec-apSyn show any detectable signal in Aplysia CNS protein extracts. The apSyn antibody immunoprecipitated a single protein band of $\sim 57 \mathrm{kDa}$ that was detected by autoradiography, after metabolic labeling of the proteins with ${ }^{32} \mathrm{P}$. No bands were detected after precipitation with the preimmune serum (Fig.
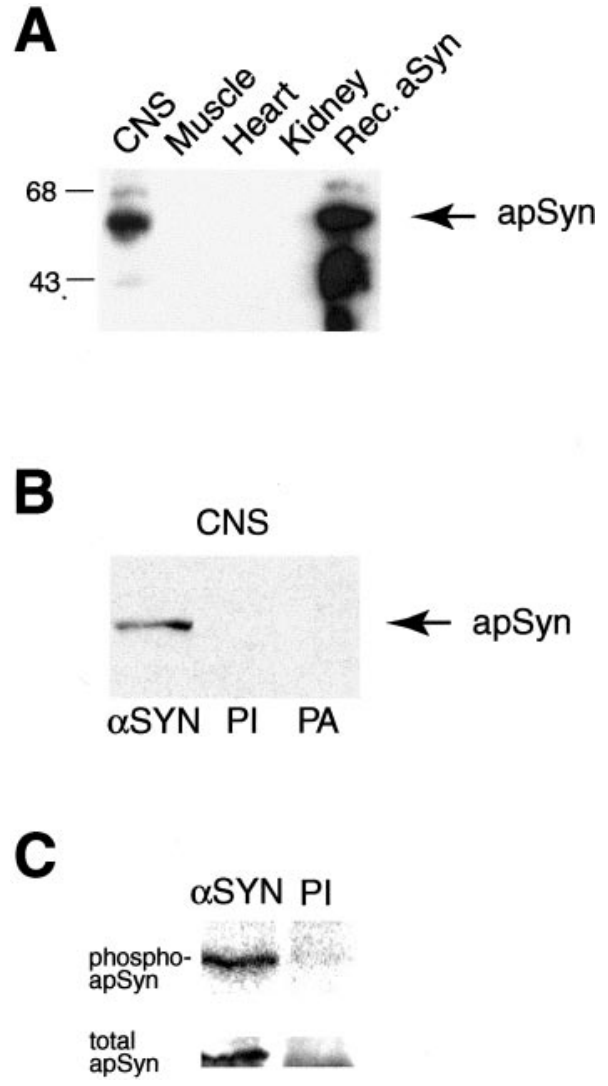

Figure 2. Western blot analysis and antibody specificity. A, A polyclonal antibody raised against rec-apSyn protein recognizes a $57 \mathrm{kDa}$ protein in CNS extracts. The lower molecular weight bands in the rec-apSyn lane are probably degradation products of the purified protein. The antibody also reacted strongly against rec-apSyn. The protein was not detectable in tissue extracts of heart, muscle, or kidney. $B$, The specificity of the antibody is demonstrated by blotting the same CNS extract with preimmune serum $(P I)$ or the antisera preabsorbed with rec-aSyn $(P A)$. $C$, The $\alpha$ Syn antibody can specifically immunoprecipitate a band of $\sim 57 \mathrm{kDa}$ from CNS extracts ( $\alpha$ Syn lane), whereas the preimmune serum cannot (PI lane). The band can be visualized by ${ }^{32} \mathrm{P}$ labeling (top panel) or immunoblotting with $\alpha$ Syn antibody (bottom panel).

$2 C$, top panel). The same band was recognized by the polyclonal antibody in a Western blot of the same membrane (Fig. 2C, bottom panel). Interestingly, as predicted by the insertion of an alternative start codon that introduces 13 additional amino acids (Fig. 1A), two immunoreactive proteins of slightly different mo- 

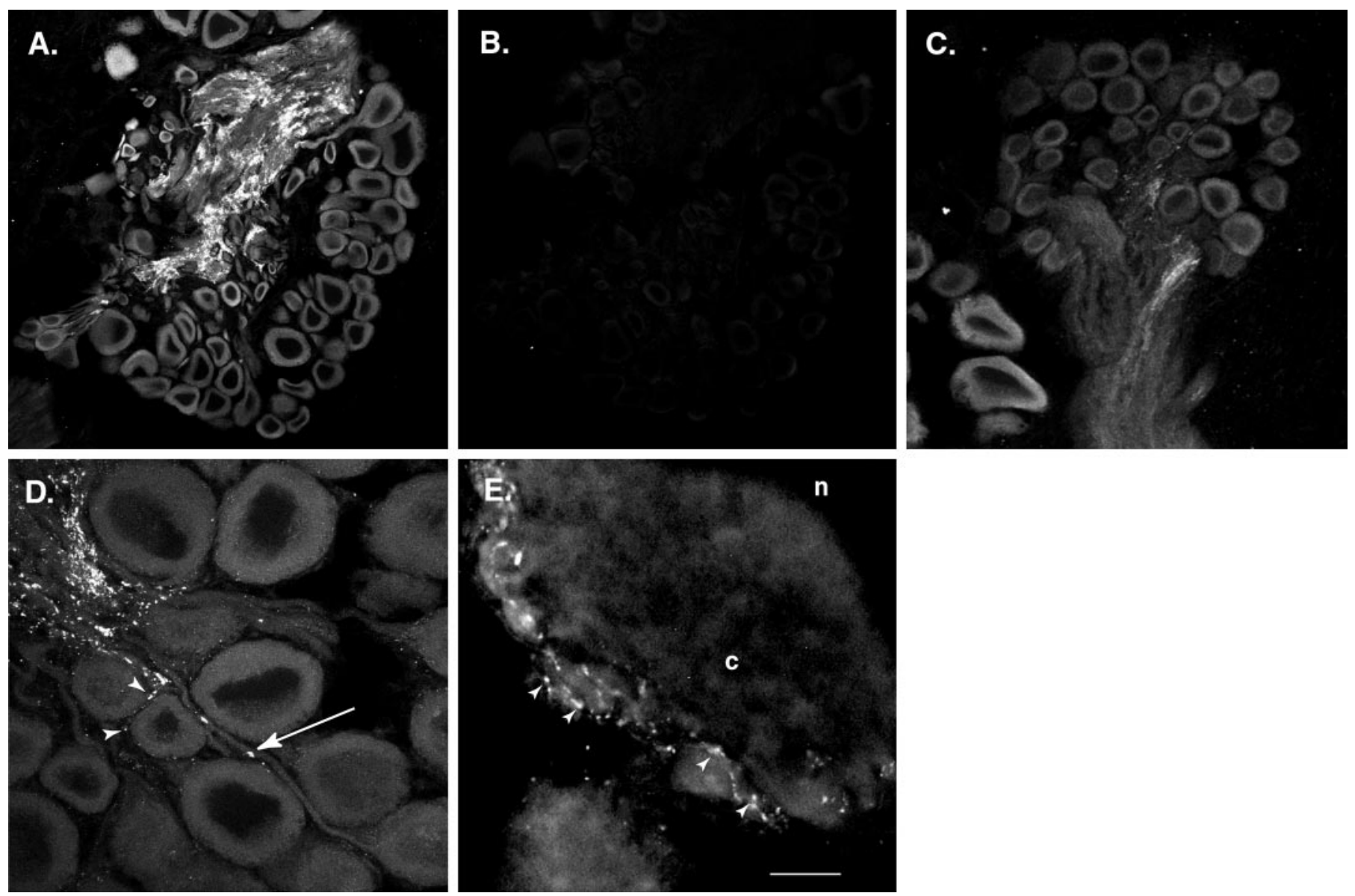

Figure 3. apSyn immunofluorescence in sections of the pleural-pedal or abdominal ganglia. $A$, Low magnification of a pedal ganglion section showing abundant staining in the neuropil. Neuron somata are also lightly stained. No staining was observed in the surrounding connective tissue. $B$, Very low level of nonspecific signal is observed in an adjacent section incubated with preimmune serum. $C$, ApSyn immunofluorescence in a section of a pleural ganglion. The most intense signal is observed in the neuropil. Neuronal somata are also immunoreactive with a lower amount of signal. $D$, Higher magnification of the section in $C$ showing the punctate nature of the signal in neurites. The arrow points to a varicosity-like region containing intense immunoreactivity. Arrowheads show similar structures on the surface of a cell body. E, High-power magnification of a large neuron from a left caudal section of an abdominal ganglion. Many brightly stained varicosities can be observed on small neurites running on the surface of the cell body (arrowheads). Cytoplasm (c) and nucleus $(n)$ are visible. Scale bar: $A, B, 150 \mu \mathrm{m} ; C, 75 \mu \mathrm{m} ; D, E, 25 \mu \mathrm{m}$.

lecular weight were detected in some CNS extracts (data not shown). This variability could reflect differential expression of these two isoforms because the doublet was more readily seen when extracts of isolated SN cell bodies were analyzed. Immunoprecipitation consistently revealed a single band (Fig. 2C). We hypothesize that this discrepancy originates from the large quantity and relative proximity of the rabbit IgG heavy chain $(50 \mathrm{kDa})$ from the immunoprecipitating antibody, which may retard the migration of the higher molecular weight proteins and compress the doublet into a single band.

\section{Cellular and subcellular distribution of apSyn in ganglia}

Immunofluorescence techniques were used to examine the cellular and subcellular distribution of apSyn in sectioned ganglia. In pleural-pedal ganglia (Fig. $3 A-D$ ) and in abdominal ganglia (Fig. $3 E$ ), apSyn immunoreactivity was present at low level in the somata of most neurons, although its intensity varied from one cell to another. Only a very low background level of staining was observed with the preimmune serum (Fig. $3 B$ ). Intense signal was observed in the neuropil, where most neuronal processes project. Varicosity-like structures along neurites were enriched in apSyn immunoreactivity, which could be observed both in the neuropil (Fig. 3D, arrow) and on the cell surface of neurons (Fig. 3D,E, arrowheads). Similar results have been obtained in other studies with antibodies raised against vertebrate synapsins (Cibelli et al., 1996).

\section{ApSyn was phosphorylated by treatment with 5-HT}

Application of 5-HT to Aplysia ganglia activates several kinases (Byrne and Kandel, 1996) and subsequently results in the phosphorylation of a number of unidentified proteins (Sweatt and Kandel, 1989; Homayouni et al., 1995). The effect of 5-HT on apSyn phosphorylation was examined by measuring incorporation of ${ }^{32} \mathrm{P}$ into apSyn protein. Desheathed pleural-pedal ganglia were metabolically labeled by incubation in ASW containing 100 $\mu \mathrm{Ci} / \mathrm{ml}{ }^{32} \mathrm{P}$. Ganglia were then exposed to $50 \mu \mathrm{M} 5-\mathrm{HT}$ (final bath concentration) or vehicle for $5 \mathrm{~min}$. ApSyn was immunoprecipitated, and ${ }^{32} \mathrm{P}$ incorporation was measured with a phosphorimager. The level of apSyn phosphorylation was significantly higher in ganglia treated with 5-HT than in control ganglia (159.89 \pm $5.4 \%$ of control; $t_{5}=6.29 ; p<0.005 ; n=6$ experiments) (Fig. 4). After autoradiography, the membrane was subjected to a Western blot analysis to ensure that equivalent amounts of total synapsin 
A
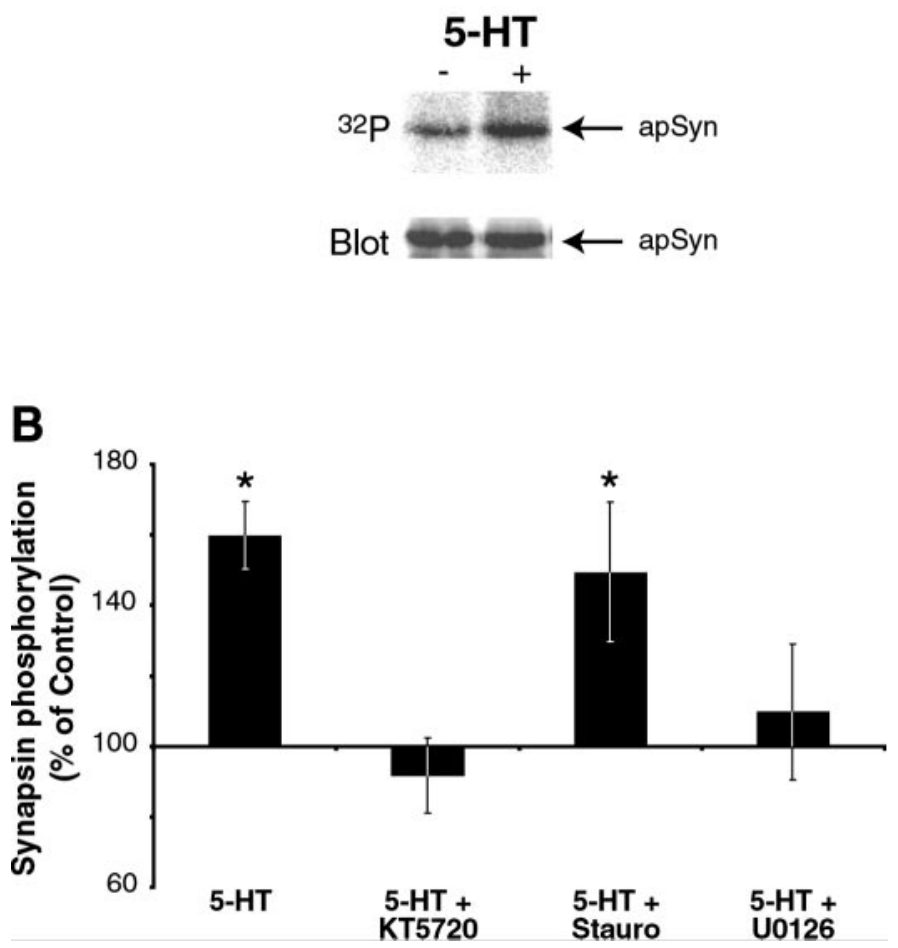

Figure 4. Phosphorylation of apSyn. A, Immunoprecipitation of ${ }^{32} \mathrm{P}$ labeled apSyn (top) shows that apSyn is phosphorylated after $5 \mathrm{~min}$ treatment with 5-HT. The immunoblot on the bottom panel shows that equivalent amounts of apSyn were immunoprecipitated from control and treated ganglia. $B$, Summary data showing quantification of apSyn phosphorylation. Results are presented as the ratio of the ${ }^{32} \mathrm{P}$ signal in the treated ganglia and control ganglia. Five minute treatment with 5-HT induces significant phosphorylation of apSyn $(n=6)$. One hour pretreatment with the PKA inhibitor KT5720 $(n=3)$ or the MAPK inhibitor U0126 $(n=6)$ inhibits 5-HT-induced phosphorylation of apSyn. Pretreatment with the PKC inhibitor staurosporine $(n=7)$ did not inhibit phosphorylation of apSyn by 5 -HT. The asterisk indicates significant difference $(p<0.05)$ from controls.

had been immunoprecipitated from control and treated ganglia (Fig. 4A, bottom panel). This result demonstrates that brief treatment with 5-HT induces phosphorylation of apSyn.

\section{5-HT-induced apSyn phosphorylation was inhibited by specific kinase inhibitors}

Specific kinase inhibitors were used to determine the kinase(s) that might be involved in apSyn phosphorylation. The putative contribution of PKA to 5-HT-induced phosphorylation was examined using KT5720, a PKA inhibitor (Gadbois et al., 1992; Simpson and Morris, 1995). At a concentration of $10 \mu \mathrm{M}$, this inhibitor reduces activity of Aplysia PKA by $\sim 80 \%$ (J. Levenson, personal communication). In the presence of $10 \mu \mathrm{M} \mathrm{KT5720,}$ 5-HT-induced apSyn phosphorylation was blocked (91.61 \pm $15.1 \%$ of baseline; $t_{2}=0.56 ; p=0.63 ; n=3$ experiments) (Fig. $4 B$ ). These results indicate that PKA contributes to 5-HTinduced phosphorylation of apSyn.

The putative involvement of PKC in 5-HT-induced apSyn phosphorylation was examined using the kinase inhibitor staurosporine. Although this compound is recognized as a general kinase inhibitor, it is believed to act more specifically on PKC in Aplysia (Sugita et al., 1992). In the presence of staurosporine (50 $\mu \mathrm{M}$ final bath concentration), 5-HT induced significant phosphor- ylation of apSyn $\left(151.80 \pm 19.7 \%\right.$ of baseline; $t_{6}=2.63 ; p<0.05$; $n=7$ experiments) (Fig. $4 B$ ). This result indicates that PKC is not part of the pathway mediating 5-HT-induced phosphorylation of synapsin.

We also examined the possible role of MAPK in 5-HT-induced phosphorylation of apSyn. In Aplysia, 5-HT leads to the activation of MAPK (Michael et al., 1998). Moreover, mammalian synapsin I is a substrate for MAPK (Jovanovic et al., 1996; Matsubara et al., 1996). The involvement of MAPK in 5-HTinduced phosphorylation of synapsin was examined using U0126, a specific inhibitor of MAP/ERK kinase (Favata et al., 1998; Davies et al., 2000) that effectively inhibits Aplysia MAPK in vitro (Chin et al., 2002). When ganglia were treated with $50 \mu \mathrm{M}$ 5-HT in the presence of $20 \mu \mathrm{M}$ U0126, apSyn phosphorylation was blocked $\left(105.07 \pm 16.5 \%\right.$ of baseline; $t_{5}=0.31 ; p=0.77 ; n=6$ experiments) (Fig. 4B). This result indicates that MAPK activity also contributes to the 5-HT-induced phosphorylation of apSyn. The finding that both the PKA and MAPK inhibitors separately and completely inhibited 5-HT-induced apSyn phosphorylation suggests that phosphorylation on PKA and MAPK sites is not additive. Rather, the activity of both kinases appears to be necessary for 5-HT-induced apSyn phosphorylation.

Although the region of mammalian synapsin I phosphorylated by CAMK II is not conserved in apSyn, we cannot exclude the possibility that CAMK II also phosphorylates apSyn. Moreover, it has been suggested that CAMK II is involved in modulation of sensorimotor synapses by 5-HT in Aplysia (Nakanishi et al., 1997). However, preliminary results indicated that pretreatment of the ganglia with $10 \mu \mathrm{M} \mathrm{KN}-62$, a specific CAMK II inhibitor, did not alter the phosphorylation of apSyn induced by 5 -HT treatment (data not shown).

\section{5-HT treatment modifies the spatial distribution of apSyn}

Phosphorylation of synapsin affects its ability to interact with SVs (Schiebler et al., 1986; Benfenati et al., 1989; Hosaka et al., 1999) and cytoskeletal elements (Benfenati et al., 1992; Matsubara et al., 1996). Ultrastructural studies at the frog neuromuscular junction indicated that the amount of SV-associated synapsin I decreases after intense electrical stimulation (Torri Tarelli et al., 1992). In addition, in presynaptic terminals of cultured hippocampal neurons, synapsin I is dispersed from the SVs during synaptic activity, in a manner controlled by synapsin I phosphorylation (Chi et al., 2001). Because 5-HT treatment induces phosphorylation of apSyn in Aplysia, we examined the effect of 5-HT treatment on synapsin distribution in the terminals of cocultures of sensory and motor neurons (Fig. 5A1,A2) and in cultures of isolated SNs (Fig. 5B1,B2).

In all cultured Aplysia neurons, brightly stained immunoreactive puncta were observed along the neurites, similar to those observed in ganglia sections (Fig. 5A1, compare inset with Fig. $3 D$ ). A more diffuse signal was also observed throughout the neuritic arborization. The strong signal observed in the soma was caused by nonspecific staining, because cultured neurons incubated with the preimmune serum showed a similar level of fluorescence (data not shown). Quantification of synapsin staining revealed an average of $4.13 \pm 0.3$ apSyn puncta per $100 \mu \mathrm{m}$ neurite in cocultured neurons ( $n=6$ cultures) (Fig. $5 A 3)$. SNs cultured in isolation exhibited an average of $11.17 \pm 2.5$ puncta/ $100 \mu \mathrm{m}(n=6$ cells) (Fig. 5B3).

Application of a $50 \mu \mathrm{M}$ bolus of 5-HT (1 $\mu \mathrm{M}$ final bath concentration) 5 min before fixation produced a dramatic reduction of 
CTRL
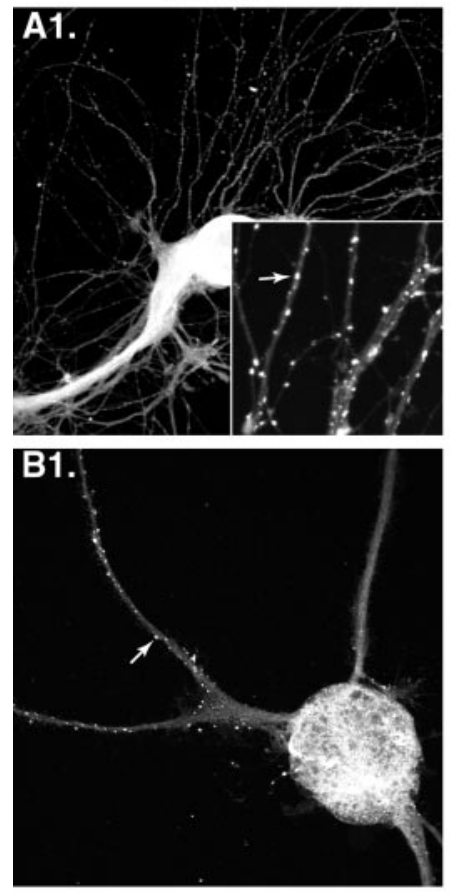

A3.

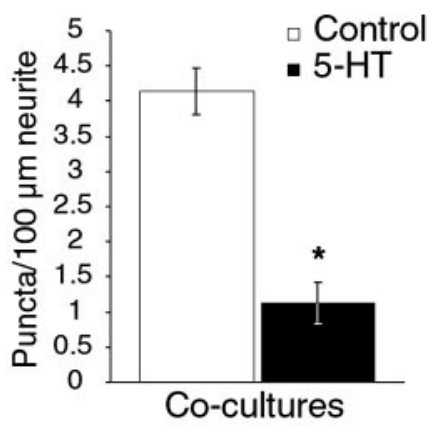

5-HT
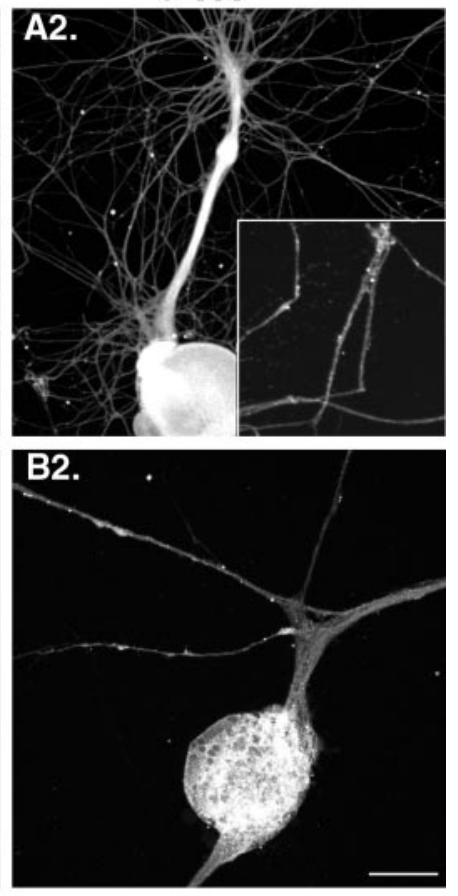

B3.

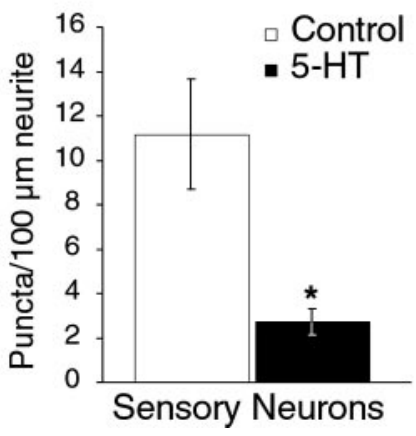

Figure 5. Treatment with 5-HT modifies subcellular distribution of apSyn. A1, ApSyn immunoreactivity in cocultures is enriched in small puncta along neurites $(C t r l)$. A2, Five minute treatment with 5-HT (50 $\mu \mathrm{M}$ bolus, $1 \mu \mathrm{M}$ final bath concentration) induces a dramatic dissipation of apSyn puncta. The inset shows a higher magnification of the neurites. The arrow points to a punctum. B1, Similar puncta were observed in isolated sensory neurons in culture (arrow). B2, After treatment with 5-HT, very few puncta could be observed along the neurites of the cells. $A 3, B 3$, Summary data presenting the number of puncta counted per $100 \mu \mathrm{m}$ of measured neurites in cocultures $(n=6$ for controls and 4 for 5-HT) $(A 3)$, and isolated sensory neurons $(n=6$ for controls and 5 for 5 -HT) (B3). Treatment of the cells with 5-HT before fixation dramatically reduced the number of puncta. Scale bar: $A, B, 75 \mu \mathrm{m}$; insets, $25 \mu \mathrm{m}$.

the number of apSyn puncta that could be detected along the neurites in cocultures $(1.13 \pm 0.3 / 100 \mu \mathrm{m} ; n=4)$ (Fig. 5A2, $A 3)$. The difference between the control and the 5-HT-treated group was statistically significant $\left(t_{8}=6.67 ; p<0.001\right)$. Similar results were obtained in isolated SNs. In the presence of 5-HT, the number of puncta that could be detected was $2.71 \pm 1.7 / 100 \mu \mathrm{m}$ $(n=5)$ (Fig. 5B2, B3). The difference between the control and the 5 -HT-treated group was statistically significant $\left(t_{9}=3.02 ; p<\right.$ $0.05)$. In cocultures, the number of apSyn puncta appeared to be reduced compared with isolated SNs (see above). Although we can only speculate on the nature of this difference, it is possible that the kinetics of puncta formation are different between the two systems, possibly because of the absence of a postsynaptic target in isolated SNs. Although the absolute number of puncta differed between the two culture systems, the reduction induced by 5 -HT was comparable (Fig. $5 A 3, B 3$ ).

Synapsin puncta presumably represent sites of vesicle accumulation. This interpretation is supported by the observation that the SV protein vesicle-associated membrane protein/synaptobrevin (VAMP) is localized in similar puncta (Fig. 6). The dispersion of synapsin puncta may represent either a dissociation of the protein from SVs after 5-HT-induced phosphorylation or a disorganization of SV clustering. To address this issue, the effects of 5-HT treatment on the distribution of VAMP were examined (Fig. 6). Unlike apSyn, the number of VAMP puncta was not affected by treatment with 5 -HT (control: $6.35 \pm 0.4$ puncta/100 $\mu \mathrm{m}$ neurite, $n=5$; 5-HT: $7.37 \pm 1$ puncta $/ 100 \mu \mathrm{m}, n=5$; $t_{8}=$ $-0.916 ; p=0.39)$. Because VAMP puncta were not altered by 5-HT treatment, vesicle clustering does not seem to be significantly affected by 5-HT. These results indicate the specificity of the effect of 5-HT on synapsin distribution and are consistent with the hypothesis that phosphorylation of apSyn results in its dissociation from SVs.

\section{The time course of 5-HT-induced dispersal of synapsin coincides with that of short-term facilitation}

5-HT induces short-term facilitation of Aplysia sensorimotor synapses (Byrne and Kandel, 1996). If synapsin is involved in this process, then its 5-HT-induced dispersion should occur at times corresponding to the effect of 5-HT on synaptic strength. In sensorimotor cocultures, a train of action potentials was elicited in a $\mathrm{SN}$ at a frequency of $1 \mathrm{~Hz}$, whereas the resulting EPSPs were monitored in a MN. After the 10th EPSP, one group of cultures received a bolus of 5-HT (1 $\mu \mathrm{M}$ final bath concentration) to induce facilitation. The control group received a corresponding number of stimuli but received a bolus of $\mathrm{H}_{2} \mathrm{O}$. Cells were fixed immediately after the 25th EPSP and processed for immunohistochemistry as described above.

Stimulation of the SN at the frequency of $1 \mathrm{~Hz}$ induced significant synaptic depression (Fig. 7A). After 25 stimuli, the EPSP was $21.00 \pm 2.3 \%$ of baseline, a decrease in synaptic strength that was statistically significant $\left(t_{2}=12.98 ; p<0.01 ; n=3\right.$; 1 st vs 25 th), and comparable to the degree of depression observed in other studies (Byrne, 1982; Eliot et al., 1994). Application of 5-HT during the stimulation train facilitated the depressed EPSPs (Fig. 7A). On average, the amplitude of EPSPs recorded after 5-HT application was $\sim 50 \%$ larger than the control group (EPSPs $14-25$; control $25.46 \pm 2.8 \%$ of baseline; 5 -HT $38.14 \pm 8.5 \%$ of baseline). This facilitation was statistically significant (repeated measures ANOVA on EPSPs $\left.14-25 ; F_{(1,10)}=17.6 ; p<0.001\right)$.

Cultures were fixed as fast as possible after the end of electrophysiological measurements, $<30 \mathrm{sec}$ after 5-HT application, and processed for immunofluorescence as above. The number of puncta in the 5-HT-treated group was significantly reduced $(1.22 \pm 0.3$ puncta $/ 100 \mu \mathrm{m}$ neurite; $n=4)$ compared with the control group $\left(3.32 \pm 0.2\right.$ puncta $/ 100 \mu \mathrm{m}$ neurite; $n=3 ; t_{5}=4.64$; $p<0.01$ ) (Fig. $7 B, C$ ). Although the effect of activity on synapsin distribution was not directly investigated, comparison of puncta density across experiments indicated that there was no obvious change in synapsin distribution in response to tonic stimulation. Because redistribution of synapsin could be frequency dependent, further experiments are necessary to address this issue. None- 


\section{A1. Control}

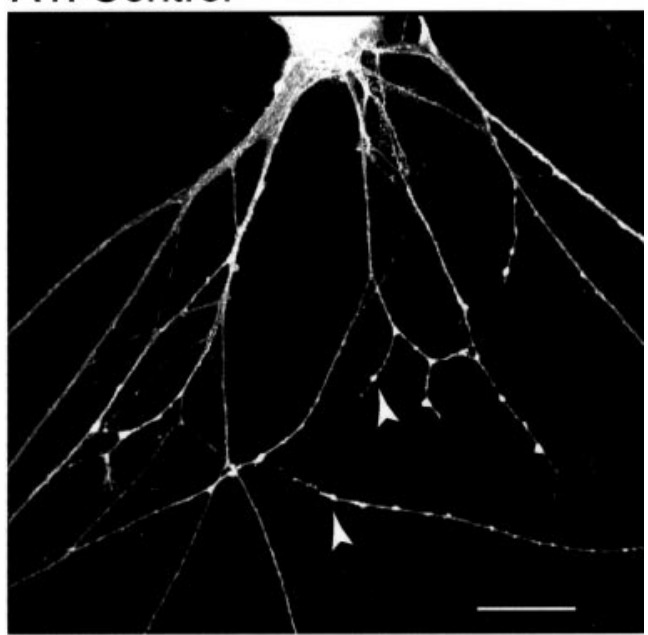

\section{A2. 5-HT}

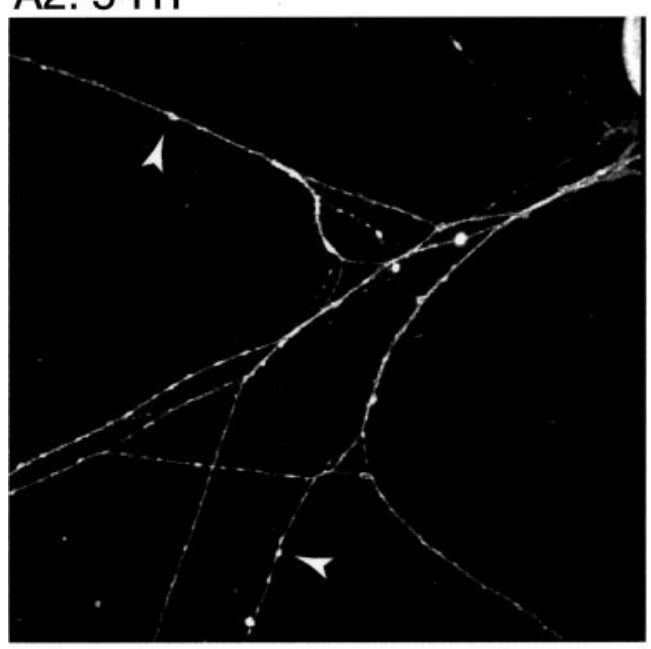

B.

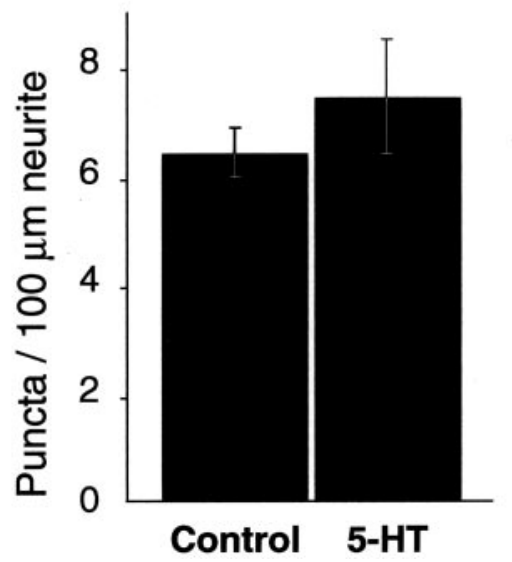

Figure 6. VAMP distribution is not altered by 5-HT. A1, Under resting conditions, the subcellular distribution of VAMP appears punctate and similar to synapsin (compare with Fig. 5B). Arrowheads point to VAMP puncta (scale bar, $25 \mu \mathrm{m}$ ). $A 2$, Treatment with 5-HT (5 min, $10 \mu \mathrm{M}$ ) does not alter VAMP localization, suggesting that short-term treatment with 5 -HT does not significantly affect the organization of SV pools. $B$, Summary data illustrating the lack of effect of 5-HT on the density of VAMP puncta $(n=5$ for controls and 5 for 5 -HT).
A.
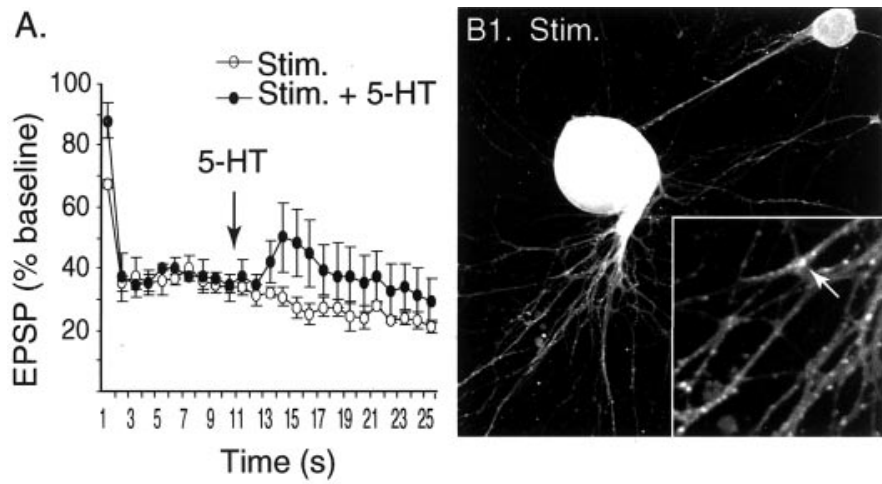

C.
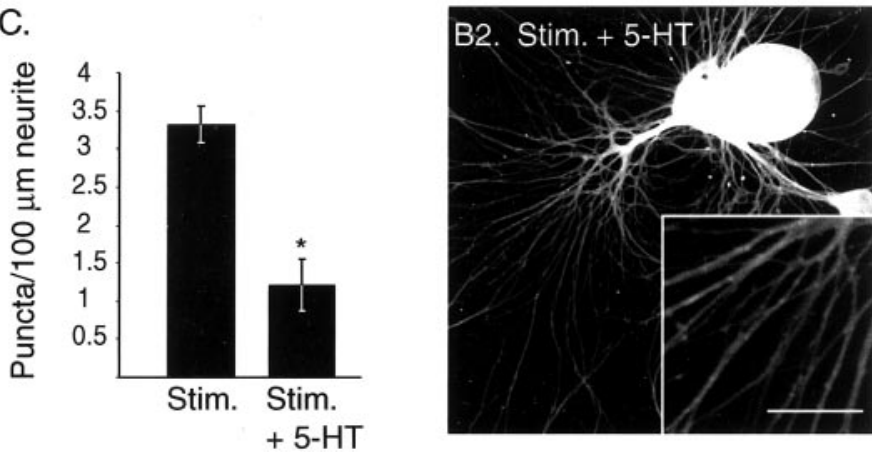

Figure 7. Distribution of apSyn puncta after low-frequency stimulation and 5-HT-induced facilitation. $A$, Averaged amplitude of EPSPs during a train of 25 stimuli $(O, n=3)$ or with 5-HT application at the 10th stimuli of the train $(0, n=4)$. Note the increase of the average amplitude of the EPSPs beginning $\sim 4 \mathrm{sec}$ after the application of 5-HT. B1, ApSyn immunoreactivity in cocultures is enriched in small puncta along the neurites of cells that received a train of 25 stimuli (Stim.). B2, Treatment with 5-HT during the train of stimuli (Stim. + 5-HT) induces dispersion of apSyn puncta. In both $B 1$ and $B 2$, cells were fixed for subsequent immunohistochemistry as fast as possible after the 25 th stimulus, $<30 \mathrm{sec}$ after exposure to 5-HT. The insets show a higher magnification of the neurites. The arrow in $B 1$ points to an apSyn punctum. Scale bar: B1, B2, $75 \mu \mathrm{m}$; insets, $25 \mu \mathrm{m}$. $C$, Summary data presenting the number of puncta counted per $100 \mu \mathrm{m}$ of measured neurites in control cocultures that received a train of 25 stimuli (Stim.) and cocultures that received the train of stimuli and were treated with 5-HT (Stim. + 5-HT).

theless, the dispersion of the synapsin puncta in response to 5-HT occurred $<30 \mathrm{sec}$ after 5-HT application, in a time domain that is relevant for short-term synaptic facilitation.

\section{5-HT-induced redistribution of apSyn is reversible}

If the dispersion of apSyn puncta in the neurites is a result of phosphorylation induced by 5-HT treatment, then this effect might be expected to be reversible after termination of 5-HT application. To determine the time course of apSyn dispersion and reclustering, SNs were treated with 5-HT (10 $\mu \mathrm{M}$ final bath concentration) for $5 \mathrm{~min}$. At the end of the treatment, 5-HT was removed by five exchanges of media, and the cells were fixed immediately, $15 \mathrm{~min}$, or $2 \mathrm{hr}$ after removal of 5-HT. Immunohistochemistry and subsequent analysis by one-way ANOVA confirmed that 5-HT induces a significant decrease in the number of apSyn puncta $\left(F_{(3,15)}=14.104 ; p<0.001\right)$ (Fig. 8). A Tukey post hoc test indicated that immediately after 5-HT application, the number of apSyn puncta was significantly reduced (control: $9.47 \pm 1.2$ puncta $/ 100 \mu \mathrm{m}$ neurite, $n=5$; immediate: $2.06 \pm 0.6$ puncta $/ 100 \mu \mathrm{m}, n=5 ; q=7.184, p<0.05)$. Fifteen minutes after 5-HT removal, the number of apSyn puncta remained significantly reduced compared with control (15 min: $3.95 \pm 1$ puncta/ 
A1. Control

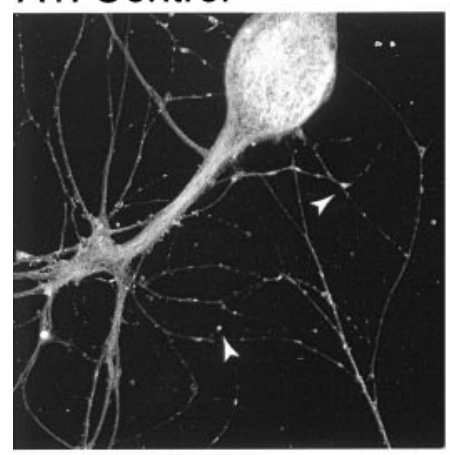

A2. $5-\mathrm{HT}$ (5 min)

A3. +15 min rinse

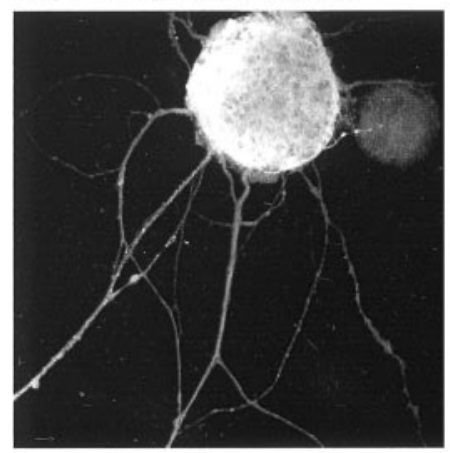

A4. $+2 \mathrm{hr}$ rinse

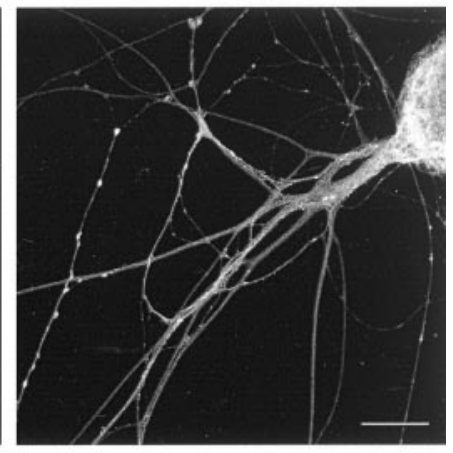

B.

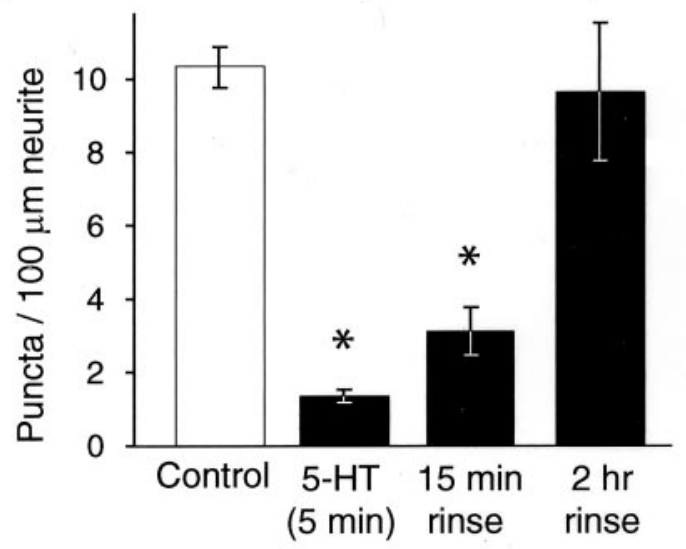

Figure 8. Time course of the effect of 5-HT treatment on apSyn subcellular distribution in isolated SNs. A, Application of 5-HT for 5 min $(A 2)$ induces a dramatic dissipation of apSyn puncta compared with control conditions (A1). Very few apSyn puncta can be observed 15 min after removal of 5 -HT $(A 3)$, but the protein distribution returned to control levels by $2 \mathrm{hr}$ after removal of the modulator (A4). Scale bar, $25 \mu \mathrm{m}$. B, Summary data presenting the number of puncta counted per $100 \mu \mathrm{m}$ of neurites. Treatment of the cells with 5 -HT before fixation dramatically reduced the number of puncta, which returned to control level by $2 \mathrm{hr}$ after termination of the treatment $(A 1, n=5 ; A 2, n=5 ; A 3, n=5 ; A 4, n=4)$.

$100 \mu \mathrm{m} ; n=5 ; q=5.35 ; p<0.05$ ) (Fig. 8B). However, by $2 \mathrm{hr}$ after 5-HT washout, the number of apSyn puncta was restored to pre-5-HT levels ( $2 \mathrm{hr}: 10.1 \pm 1.5$ puncta $/ 100 \mu \mathrm{m} ; n=4 ; q=0.57$; $p=0.977)$. These results indicate that the change in localization of synapsin attributable to 5-HT is dynamic and reversible.

\section{5-HT-induced change of apSyn spatial distribution was impaired by specific kinase inhibitors}

To further investigate the role of PKA and MAPK in the effects of 5-HT on apSyn, we examined the effects of specific inhibitors on the modification of apSyn localization. Isolated SNs were treated with $10 \mu \mathrm{M}$ KT5720, $20 \mu \mathrm{M}$ U0126, or vehicle for $1 \mathrm{hr}$ before treatment with 5-HT (10 $\mu \mathrm{M}$ final bath concentration). Cultures were subsequently fixed and immunostained for apSyn (Fig. 9). Analysis by two-way ANOVA indicated a significant effect of 5-HT $\left(F_{(1,61)}=6.63 ; p<0.05\right)$, confirming earlier observations (Figs. 5, 7, 8). In addition, the kinase inhibitors significantly impaired the effect of 5-HT on the distribution of apSyn puncta $\left(F_{(2,61)}=15.24 ; p<0.001\right)$. Tukey post hoc analysis confirmed that 5-HT dramatically decreased the number of apSyn puncta in the vehicle-treated group (DMSO-alone: $7.28 \pm 0.6$ puncta $/ 100 \mu \mathrm{m}$ neurite, $n=14$; DMSO-5-HT: $2.27 \pm 0.4, n=12$; $q=7.343 ; p<0.05$ ) (Fig. 9A). This effect was blocked by KT5720 (KT5720-alone: $6.67 \pm 0.8, n=12$; KT5720-5-HT: $7.62 \pm 1.3$, $n=11 ; q=1.32 ; p=0.936$ ) (Fig. 9B), suggesting that PKA may mediate the effect of 5-HT on apSyn spatial distribution, presumably through phosphorylation of the PKA/CAMK I/IV site. MAPK may also play a role in 5-HT-induced apSyn dispersion, although its specific role is less clear. U0126 blocked the 5-HTinduced change in the number of apSyn puncta (U0126-alone: $3.25 \pm 0.5, n=9$; U0126-5-HT: $2.62 \pm 0.3 ; n=9 ; q=0.774 ; p=$ 0.994) (Fig. 9C), indicating that MAPK may be involved in the modification of apSyn localization. However, application of U0126 alone had a significant effect on the basal number of apSyn puncta compared with DMSO treatment $(q=1.834 ; p<0.05)$ (Fig. 9A1-C1). Therefore, the effect of U0126 on the localization of apSyn suggests that basal MAPK activity may contribute to the proper localization of apSyn at synaptic terminals.

\section{DISCUSSION}

\section{Structure of apSyn}

Aplysia synapsin was cloned using sequence conservation in the $\mathrm{C}$ domain of vertebrate and invertebrate synapsin. The similarities in domain arrangement, sequence conservation of the central $\mathrm{C}$ domain, appearance, and high sequence homology of the $\mathrm{N}$-terminal PKA phosphorylation site, as well as the conservation of at least three intron-exon boundaries with mammalian synapsin I gene (Südhof, 1990), support the common ancestry of these proteins.

Despite some differences, Aplysia synapsin shares many important similarities with its mammalian homologs. The nearly perfect conservation of the phosphorylation site in domain A supports the hypothesis that this short N-terminal domain has a significant role in the function of the protein. This domain appears to regulate the association of the protein with SVs through phosphorylation of the serine residue (Hosaka et al., 1999; Chi et al., 2001), a hypothesis supported by the fact that inhibition of PKA blocked 5-HT-induced dispersion of apSyn. $\mathrm{Ser}_{9}$ in domain A is part of the only PKA phosphorylation consensus sequence found in apSyn (see on-line supplemental Fig. S1).

Although the primary structure is not well conserved in the region immediately following domain $\mathrm{A}$, it does have important similarities to domain B of vertebrates (Matsubara et al., 1996). This region of apSyn is rich in serine and proline residues and shows two contiguous putative MAPK phosphorylation sites. These sites are potentially important in Aplysia, because 5-HTinduced phosphorylation of apSyn is at least partially accomplished by MAPK (Fig. 4). Moreover, inhibition of basal MAPK activity seems to affect apSyn distribution, and MAPK activity may also be important for the redistribution of apSyn induced by short-term treatment with 5-HT (Fig. 9). 


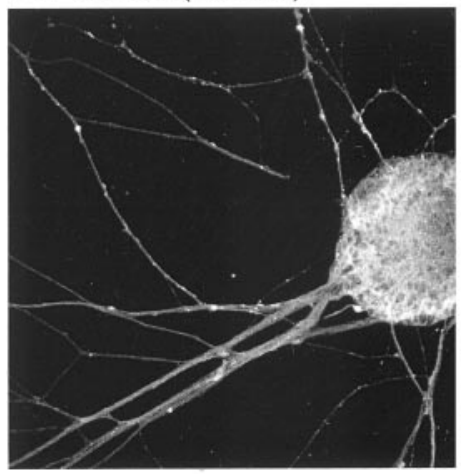

bution induced by treatment with 5 HT is inhibited by the PKA inhibitor KT5720 and the MAPK cascade inhibitor U0126. $A$, DMSO (vehicle for inhibitors) did not affect the ability of 5-HT to induce redistribution of apSyn in cultured SNs after a 5 min incubation period $(A 3, D M S O: n=14 ; D M S O+$ 5-HT: $n=12)$. $B$, One hour treatment with the PKA inhibitor KT5720 completely inhibited the ability of 5-HT to induce redistribution of apSyn (B3, KT5720: $n=12 ;$ KT5720 + 5-HT: $n=$ 11). $C$, The MEK inhibitor U0126 also appeared to preclude the effects of 5-HT, although the number of puncta before 5-HT application was altered by the presence of the inhibitor $(C 3$, U0126: $n=9$; U0126 + 5-HT: $n=9)$. Scale bar, $25 \mu \mathrm{m}$.
A1. DMSO (control)

B1. KT5720

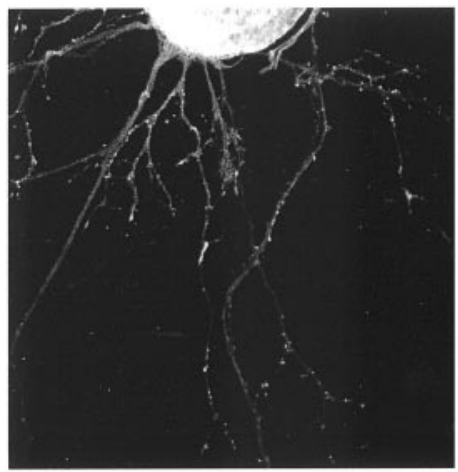

C1. U0126

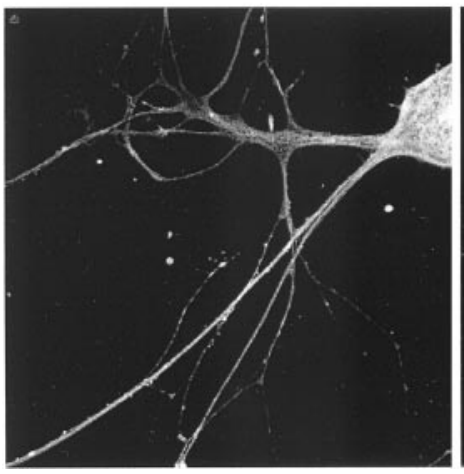

A2. $\mathrm{DMSO}+5-\mathrm{HT}$

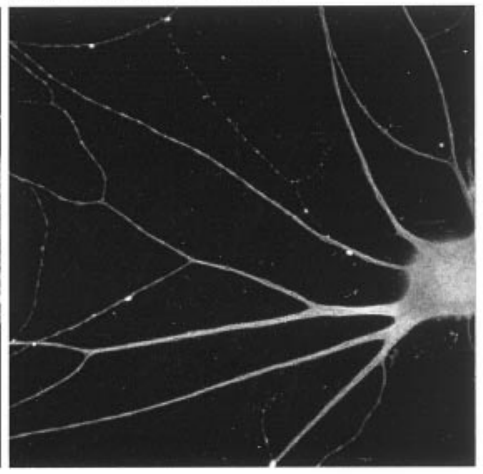

B2. KT5720 + 5-HT

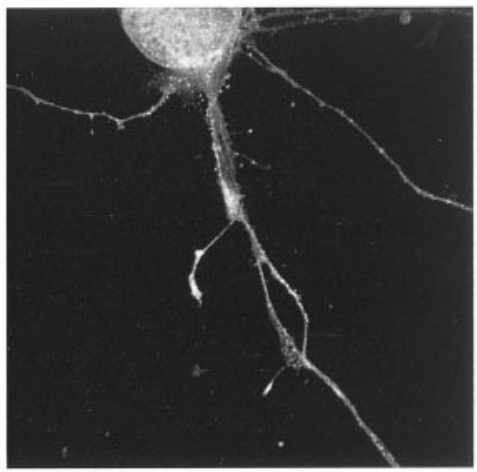

A3.

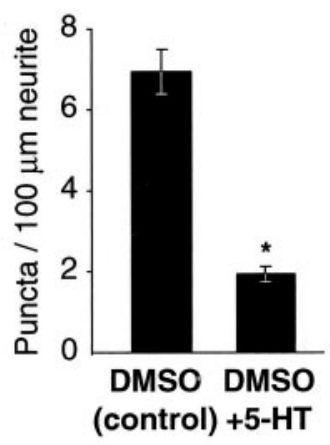

B3.

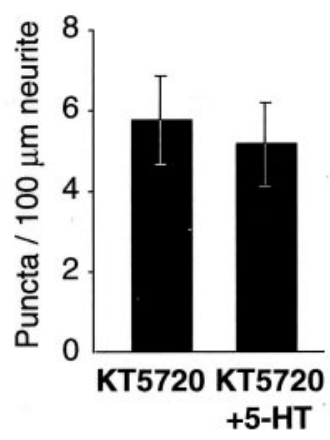

C3.

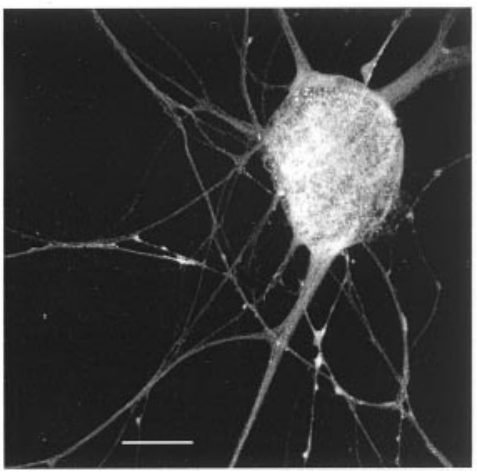

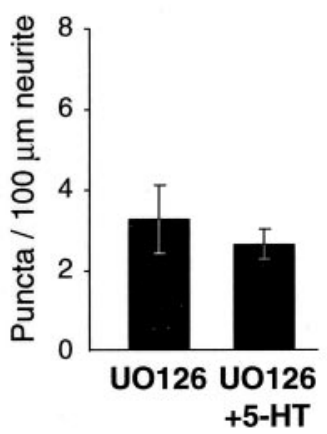

\section{5-HT-induced apSyn phosphorylation is both PKA and MAPK dependent}

Application of 5-HT to sensory neurons of Aplysia induces both short- and long-term facilitation of the sensorimotor synapse (Byrne and Kandel, 1996; Kandel, 2001). The molecular events leading to facilitation involve activation of several kinases by 5-HT. In turn, these kinases catalyze the phosphorylation of several proteins, but only a few of these have been identified (Homayouni et al., 1997). The present results indicate that synapsin is one of these substrates.

apSyn was phosphorylated in ganglia after treatment with 5-HT. apSyn phosphorylation by 5-HT was completely inhibited by KT5720, suggesting that at least part of apSyn phosphorylation is attributable to PKA. Previous studies conducted in squid using presynaptic injection of bovine synapsin I showed that the capacity of unphosphorylated synapsin to inhibit neurotransmitter release was unchanged by phosphorylation at the PKA site (Llinás et al., 1985, 1991). However, more recent data obtained in rat synaptosomal preparations demonstrated that the association of all synapsin isoforms with SVs was disrupted when the protein was phosphorylated at the PKA/CAMK I/IV site (Hosaka et al., 1999).

Our data suggest that an additional pathway links 5-HT and synapsin phosphorylation. When ganglia were treated with U0126, a specific inhibitor of the MAPK pathway (Favata et al., 1998; Davies et al., 2000), treatment with 5-HT failed to induce apSyn phosphorylation. Thus, activation of MAPK by 5-HT is also necessary for apSyn phosphorylation. Because both inhibitors of PKA and MAPK completely blocked apSyn phosphorylation, both kinases may be necessary for the modulation of apSyn by 5 -HT. We cannot presently determine whether these enzymes work sequentially or simultaneously in the modulation of apSyn. The observation that each kinase inhibitor completely inhibits phosphorylation suggests that cross talk between the PKA and MAPK pathways exists. Alternatively, the accessibility of one phosphorylation site might depend on phosphorylation of another site. Because U0126 reduces the basal level of MAPK activity (Chin et al., 2002), it is possible that maintenance of basal apSyn 
phosphorylation is controlled by MAPK and necessary for further phosphorylation of the protein that controls its interactions with other molecules. This hypothesis is consistent with our observation that treatment with a MAPK inhibitor disrupts the normal subcellular distribution of apSyn (Fig. 9C).

Previous studies have shown that phosphorylation by MAPK controls cytoskeletal interactions (Matsubara et al., 1996; Jovanovic et al., 2000). Phosphorylation of mammalian synapsin I by MAPK attenuated the binding of synapsin to actin filaments, as did CAMK II-induced phosphorylation of synapsin (Matsubara et al., 1996). Recent work in invertebrate synaptic preparations suggested that in addition to its better understood role in mobilization, synapsin might have a role in the regulation of the fusion process (Hilfiker et al., 1998; Humeau et al., 2001). Because actin is predominantly found at the active zone in presynaptic terminals (Morales et al., 2000), synapsin could function to regulate recycling vesicles in a MAPK-dependent way.

Our results provide evidence for the importance of MAPK activity in the modulation of neurotransmitter release. Recent findings by Jovanovic et al. (2000) indicated that synapsin phosphorylation by MAPK is correlated with BDNF-induced enhancement of neurotransmitter release in rat and mouse synaptosomes. The finding that U0126 attenuated 5-HT-induced short-term synaptic facilitation at depressed but not nondepressed synapses (Phares and Byrne, 2001) further supports the specific involvement of MAPK in short-term facilitation of the sensorimotor synapse. Finally, it is particularly interesting that TGF- $\beta 1$, like 5-HT, leads to facilitation of the sensory-motor synapse in Aplysia as well as phosphorylation of synapsin. Both effects are blocked by U0126 (Chin et al., 2002). As is the case with 5-HT-induced facilitation, the MAPK-dependent effect of TGF- $\beta 1$ on synaptic facilitation is evident only if the release machinery is challenged (Phares and Byrne, 2001; Chin et al., 2002).

\section{ApSyn phosphorylation disrupts its association to SVs}

Our results indicate that 5-HT treatment induces both apSyn phosphorylation and its subcellular redistribution. Because 5-HT does not lead to a significant dispersion of the intrinsic SV protein VAMP (Fig. 6), it appears that the dispersion of apSyn is a consequence of the loss of its association with SVs. Indeed, after high-frequency stimulation of the frog neuromuscular junction, ultrastructural studies showed that $30 \%$ of synapsin was lost from the surface of SVs (Torri Tarelli et al., 1992). This loss presumably occurs after phosphorylation of synapsin I by CAMK I and/or II, activated by the massive entry of calcium during the stimulation. The role of CAMKs was recently confirmed by Chi et al. (2001), who showed that synapsin I dispersed in hippocampal synapses in response to activity. This dispersion showed slower kinetics after mutation of one or several synapsin phosphorylation sites. Most importantly, synapsin mutations resulted in slower kinetics of synaptic vesicle pool turnover, suggesting that synapsin regulates neurotransmitter release via its interaction with SVs.

Evidence for a role of synapsin in the regulation of fusioncompetent SVs comes from a study on synapsin knock-out mice, which suggested that synapsin regulates the increase in the supply of fusion-competent SVs at the active zone under conditions of accelerated vesicle traffic (Rosahl et al., 1995). By injecting antibodies against synapsin into cholinergic neurons of the buccal ganglion in Aplysia, Humeau et al. (2001) showed that synapsin also regulates secretory responses to high-frequency stimulation.

In Aplysia, it has been suggested that a molecular mechanism responsible for synaptic facilitation induced by 5-HT may be vesicle mobilization (Byrne and Kandel, 1996). This mechanism would be particularly important at synapses that have been previously depressed by low-frequency stimulation (Gingrich and Byrne, 1985; Braha et al., 1990; Klein, 1994). The observation that 5-HT application disrupts synapsin puncta provides evidence consistent with the possibility that the regulation of synapsin may contribute to 5-HT-induced presynaptic facilitation. Because synapsin is believed to regulate the availability of SVs, the dispersion of synapsin by 5-HT is consistent with the hypothesis that vesicle mobilization may be a molecular component of facilitation.

Moreover, 5-HT-induced dispersion of synapsin puncta occurs in a time frame that is relevant for short-term facilitation. The dispersion occurred within $30 \mathrm{sec}$ of 5-HT application and lasted $<2$ hr. Previous results indicated that short-term facilitation induced by 5-HT occurs very rapidly after exposure to 5-HT (Fig. 7) and usually lasts <30 min (Eliot et al., 1994; Mauelshagen et al., 1996; Sutton and Carew, 2000). The later temporal domain of the effect on synapsin puncta may not correspond directly to the time course of facilitation, however. The effect on synapsin puncta persisted somewhat longer than facilitation itself, which has been reported to be greatly reduced after 15-30 min (Fig. 8) (Eliot et al., 1994; Mauelshagen et al., 1996; Sutton and Carew, 2000). We hypothesize that the dispersion of synapsin allows for the mobilization of vesicles, rather than triggering mobilization itself, and thus the time course of dispersion of synapsin puncta need not directly parallel that of facilitation. However, it is important that the time course of the dispersion of synapsin puncta allow for facilitation induced by 5-HT. Thus, the dispersion of synapsin puncta must persist at least as long as, or longer than, facilitation. The present results demonstrate that synapsin is regulated by $5-\mathrm{HT}$ in an appropriate time frame to indicate that this regulation might contribute to the onset of facilitation by allowing vesicle mobilization.

\section{REFERENCES}

Angers A, Bean AJ, Byrne JH (1999) Cloning and molecular characterization of Aplysia synaptic vesicle protein synapsin. Soc Neurosci Abstr 25:1749.

Angers A, Chin J, Cleary LJ, Byrne JH (2000) 5-HT treatment induces redistribution of Aplysia synapsin. Soc Neurosci Abstr 26:881.

Bähler M, Greengard P (1987) Synapsin I bundles F-actin in a phosphorylation-dependent manner. Nature 326:704-707.

Benfenati F, Bahler M, Jahn R, Greengard P (1989) Interactions of synapsin I with small synaptic vesicles: distinct sites in synapsin I bind to vesicle phospholipids and vesicle proteins. J Cell Biol 108:1863-1872.

Benfenati F, Valtorta F, Chieregatti E, Greengard P (1992) Interaction of free and synaptic vesicle-bound synapsin I with F-actin. Neuron 8:377-386.

Braha O, Dale N, Hochner B, Klein M, Abrams TW, Kandel ER (1990) Second messengers involved in the two processes of presynaptic facilitation that contribute to sensitization and dishabituation in Aplysia sensory neurons. Proc Natl Acad Sci USA 87:2040-2044.

Byrne JH (1982) Analysis of synaptic depression contributing to habituation of gill-withdrawal reflex in Aplysia californica. J Neurophysiol 48:431-438

Byrne JH, Kandel ER (1996) Presynaptic facilitation revisited: state and time dependence. J Neurosci 16:425-435.

Chi P, Greengard P, Ryan TA (2001) Synapsin dispersion and reclustering during synaptic activity. Nat Neurosci 4:1187-1193.

Chin J, Angers A, Cleary LJ, Eskin A, Byrne JH (1999) TGF- $\beta 1$ in Aplysia: role in long-term changes in the excitability of sensory neurons and distribution of T $\beta$ R-II-like immunoreactivity. Learn Mem 6:317-330.

Chin J, Angers A, Cleary LJ, Eskin A, Byrne JH (2002) Transforming growth factor $\beta 1$ alters synapsin distribution and modulates synaptic depression in Aplysia. J Neurosci 22:RC220(1-6).

Cibelli G, Ghirardi M, Onofri F, Casadio A, Benfenati F, Montarolo PG Vitiello F (1996) Synapsin-like molecules in Aplysia punctata and Helix pomatia: identification and distribution in the nervous system and during the formation of synaptic contacts in vitro. Eur $\mathbf{J}$ Neurosci $8: 2530-2543$. 
Davies SP, Reddy H, Caivano M, Cohen P (2000) Specificity and mechanism of action of some commonly used protein kinase inhibitors. Biochem J 351:95-105.

De Camilli P, Benfenati F, Valtorta F, Greengard P (1990) The synapsins. Annu Rev Cell Biol 6:433-460.

Eliot LS, Hawkins RD, Kandel ER, Schacher S (1994) Pairing-specific, activity-dependent presynaptic facilitation at Aplysia sensory-motor neuron synapses in isolated cell culture. J Neurosci 14:368-383.

Favata MF, Horiuchi KY, Manos EJ, Daulerio AJ, Stradley DA, Feeser WS, Van Dyk DE, Pitts WJ, Earl RA, Hobbs F, Copeland RA, Magolda RL, Scherle PA, Trzaskos JM (1998) Identification of a novel inhibitor of mitogen-activated protein kinase kinase. J Biol Chem 273:18623-18632.

Fioravante D, Chin J, Angers A, Cleary LJ, Byrne JH (2001) Time course and kinase involvement in 5-HT-induced redistribution of synapsin in Aplysia. Soc Neurosci Abstr 27:1016.

Gadbois DM, Crissman HA, Tobey RA, Bradbury EM (1992) Multiple kinase arrest points in the G1 phase of nontransformed mammalian cells are absent in transformed cells. Proc Natl Acad Sci USA 89:8626-8630.

Gingrich KJ, Byrne JH (1985) Simulation of synaptic depression, posttetanic potentiation, and presynaptic facilitation of synaptic potentials from sensory neurons mediating gill-withdrawal reflex in Aplysia. J Neurophysiol 53:652-669.

Greengard P, Valtorta F, Czernik AJ, Benfenati F (1993) Synaptic vesicle phosphoproteins and regulation of synaptic function. Science 259:780-785.

Hilfiker S, Schweizer FE, Kao HT, Czernik AJ, Greengard P, Augustine GJ (1998) Two sites of action for synapsin domain $E$ in regulating neurotransmitter release. Nat Neurosci 1:29-35.

Homayouni R, Byrne JH, Eskin A (1995) Dynamics of protein phosphorylation in sensory neurons of Aplysia. J Neurosci 15:429-438.

Homayouni R, Nunez-Regueiro M, Byrne JH, Eskin A (1997) Identification of two phosphoproteins affected by serotonin in Aplysia sensory neurons. Brain Res 750:87-94.

Hosaka M, Hammer RE, Südhof TC (1999) A phospho-switch controls the dynamic association of synapsins with synaptic vesicles. Neuron 24:377-387.

Humeau Y, Doussau F, Vitiello F, Greengard P, Benfenati F, Poulain B (2001) Synapsin controls both reserve and releasable synaptic vesicle pools during neuronal activity and short-term plasticity in Aplysia. J Neurosci 21:4195-4206.

Huttner WB, Schiebler W, Greengard P, De Camilli P (1983) Synapsin I (protein I), a nerve terminal-specific phosphoprotein. III. Its association with synaptic vesicles studied in a highly purified synaptic vesicle preparation. J Cell Biol 96:1374-1388.

Jovanovic JN, Benfenati F, Siow YL, Sihra TS, Sanghera JS, Pelech SL, Greengard P, Czernik AJ (1996) Neurotrophins stimulate phosphorylation of synapsin I by MAP kinase and regulate synapsin I-actin interactions. Proc Natl Acad Sci USA 93:3679-3683.

Jovanovic JN, Czernik AJ, Fienberg AA, Greengard P, Sihra TS (2000) Synapsins as mediators of BDNF-enhanced neurotransmitter release. Nat Neurosci 3:323-329.

Kandel E (2001) The molecular biology of memory storage: a dialogue between genes and synapses. Science 294:1030-1038.

Kao HT, Porton B, Hilfiker S, Stefani G, Pieribone VA, DeSalle R, Greengard P (1999) Molecular evolution of the synapsin gene family. J Exp Zool 285:360-377.

Klagges BR, Heimbeck G, Godenschwege TA, Hofbauer A, Pflugfelder GO, Reifegerste R, Reisch D, Schaupp M, Buchner S, Buchner E (1996) Invertebrate synapsins: a single gene codes for several isoforms in Drosophila. J Neurosci 16:3154-3165.

Klein M (1994) Synaptic augmentation by 5-HT at rested Aplysia sensorimotor synapses: independence of action potential prolongation. Neuron 13:159-166.

Li L, Chin LS, Shupliakov O, Brodin L, Sihra TS, Hvalby O, Jensen V, Zheng D, McNamara JO, Greengard P, Anderson P (1995) Impairment of synaptic vesicle clustering and of synaptic transmission, and increased seizure propensity, in synapsin I-deficient mice. Proc Natl Acad Sci USA 92:9235-9239.

Llinás R, McGuinness TL, Leonard CS, Sugimori M, Greengard P (1985) Intraterminal injection of synapsin I or calcium/calmodulindependent protein kinase II alters neurotransmitter release at the squid giant synapse. Proc Natl Acad Sci USA 82:3035-3039.

Llinás R, Gruner JA, Sugimori M, McGuinness TL, Greengard P (1991) Regulation by synapsin I, $\mathrm{Ca}^{2+}$-calmodulin-dependent protein kinase
II of the transmitter release in squid giant synapse. $\mathrm{J}$ Physiol (Lond) 436:257-282.

Martin KC, Michael D, Rose JC, Barad M, Casadio A, Zhu H, Kandel ER (1997a) MAP kinase translocates into the nucleus of the presynaptic cell and is required for long-term facilitation in Aplysia. Neuron 18:899-912.

Martin KC, Casadio A, Zhu H, Yaping E, Rose JC, Chen M, Bailey CH, Kandel ER (1997b) Synapse-specific long-term facilitation of Aplysia sensory to motor neuron synapses: a function for local protein synthesis in memory storage. Cell 91:927-938.

Matsubara M, Kusubata M, Ishiguro K, Uchida T, Titani K, Taniguchi H (1996) Site-specific phosphorylation of synapsin I by mitogen-activated protein kinase and $\mathrm{Cdk} 5$ and its effects on physiological functions. J Biol Chem 271:21108-21113.

Mauelshagen J, Parker GR, Carew TJ (1996) Dynamics of induction and expression of long-term synaptic facilitation in Aplysia. J Neurosci 16:7099-7108.

Michael D, Martin KC, Seger R, Ning MM, Baston R, Kandel ER (1998) Repeated pulses of serotonin required for long-term facilitation activate mitogen-activated protein kinase in sensory neurons of Aplysia. Proc Natl Acad Sci USA 95:1864-1869.

Morales M, Colicos M, Goda Y (2000) Actin-dependent regulation of neurotransmitter release at central synapses. Neuron 27:539-550.

Nakanishi K, Zhang F, Baxter DA, Eskin A, Byrne JH (1997) Role of calcium-calmodulin-dependent protein kinase II in modulation of sensorimotor synapses in Aplysia. J Neurophysiol 78:409-416.

Phares GA, Byrne JH (2001) MAPK is involved in serotonin-induced short-term facilitation of Aplysia sensorimotor synapses. Soc Neurosci Abstr 27:1703.

Rayport SG, Schacher S (1986) Synaptic plasticity in vitro: cell culture of identified Aplysia neurons mediating short-term habituation and sensitization. J Neurosci 6:759-763.

Rosahl TW, Geppert M, Spillane D, Herz J, Hammer RE, Malenka RC, Südhof TC (1993) Short-term synaptic plasticity is altered in mice lacking synapsin I. Cell 75:661-670.

Rosahl TW, Spillane D, Missler M, Herz J, Selig DK, Wolff JR, Hammer RE, Malenka RC, Südhof TC (1995) Essential functions of synapsins I and II in synaptic vesicle regulation. Nature 375:488-493.

Schacher S, Proshansky E (1983) Neurite regeneration by Aplysia neurons in dissociated cell culture: modulation by Aplysia hemolymph and the presence of the initial axonal segment. J Neurosci 3:2403-2413.

Schiebler W, Jahn R, Doucet JP, Rothlein J, Greengard P (1986) Characterization of synapsin I binding to small synaptic vesicles. J Biol Chem 261:8383-8390.

Simpson CS, Morris BJ (1995) Induction of c-fos and zif/268 gene expression in rat striatal neurons, following stimulation of D1-like dopamine receptors, involves protein kinase $\mathrm{A}$ and protein kinase C. Neuroscience 68:97-106.

Südhof TC (1990) The structure of the human synapsin I gene and protein. J Biol Chem 265:7849-7852.

Südhof TC, Czernik AJ, Kao HT, Takei K, Johnston PA, Horiuchi A, Kanazir SD, Wagner MA, Perin MS, De Camilli P, Greengard P (1989) Synapsins: mosaics of shared and individual domains in a family of synaptic vesicle phosphoproteins. Science 245:1474-1480.

Sugita S, Goldsmith JR, Baxter DA, Byrne JH (1992) Involvement of protein kinase $\mathrm{C}$ in serotonin-induced spike broadening and synaptic facilitation in sensorimotor connections of Aplysia. J Neurophysiol 68:643-651.

Sutton MA, Carew TJ (2000) Parallel molecular pathways mediate expression of distinct forms of intermediate-term facilitation at tail sensory-motor synapses in Aplysia. Neuron 26:219-231.

Sweatt JD, Kandel ER (1989) Persistent and transcriptionally dependent increase in protein phosphorylation in long-term facilitation of Aplysia sensory neurons. Nature 339:51-54.

Torri Tarelli F, Bossi M, Fesce R, Greengard P, Valtorta F (1992) Synapsin I partially dissociates from synaptic vesicles during exocytosis induced by electrical stimulation. Neuron 9:1143-1153.

Turner KM, Burgoyne RD, Morgan A (1999) Protein phosphorylation and the regulation of synaptic membrane traffic. Trends Neurosci 22:459-464.

Valtorta F, Villa A, Jahn R, De Camilli P, Greengard P, Ceccarelli B (1988) Localization of synapsin I at the frog neuromuscular junction. Neuroscience 24:593-603.

Zimmer WE, Z hao Y, Sikorski AF, Critz SD, Sangerman J, Elferink LA, $\mathrm{Xu}$ XS, Goodman SR (2000) The domain of brain beta-spectrin responsible for synaptic vesicle association is essential for synaptic transmission. Brain Res 881:18-27. 